\title{
What Is a Good Legislative Definition?
}

\author{
Adrian Sgarbi ${ }^{1,2}$ \\ ${ }^{1}$ Department of Law, Pontificia Universidade Católica, Rio de Janeiro, Brazil \\ ${ }^{2}$ Department of Private Law, Universitat of Girona, Girona, Spain \\ Email: asgarbi@puc-rio.br
}

Received October $9^{\text {th }}$, 2012; revised November $10^{\text {th }}$, 2012; accepted November $17^{\text {th }}, 2012$

\begin{abstract}
When normative authorities (that is to say, "Legislators") assume the task of assigning the meaning of normative texts, they use, fundamentally, two techniques: these are called "interpretative laws" and "legislative definitions". In this study, relating to the research "problems of production and normative performance", we deal with the analysis of definitions in the legal field.
\end{abstract}

Keywords: Jurisprudence; Legislative Definition; Legislative Drafting

\section{Introduction}

The Roman jurist Giavoleno Prisco (1st Century AD), in a well-known maxim, established that "omnis definitio in iure civili periculosa est" ${ }^{1}$. In one sense somewhat ordinary, this maxim has been repeatedly cited with the objective of condemning any and every foray into definition on the part of the legislator.

Despite this opposition, there are clear legislative examples of dispositions which define. It seems, therefore, that all of this requires a more detailed analysis.

Thus, with this specific objective, in item 1 we shall begin with an uncontroversial concept of definition so that afterwards we may deal with the understanding of legislative definition in particular (item 5). Then, we will look at its propositions (item 2 ), and the classification and function of legislative definitions (item 3). In the successive items, based on some necessary distinctions between "norms", "normative dispositions", and "networks of disposition" (item 4), we will relate the theme of legislative definition to its styling. Moreover, we will deal with the question of the difference between the "legislative" definitions and the definitions resulting from "legal doctrine" (item 7) so that, in the end, we may question if this must be defined by the legislator (item 8). In the sequel, we concentrate our forces on the analysis of the common pathologies in legal definitions (item 9), in how to go about avoiding them (item 10).

\section{What Is a Definition?}

It is said that a "vocable" is a word or term. A "statement" is a sequence of signs inscribed by some physical means (sounds and images), be it oral enunciation (speech) or written (vocables); it is the product, the result of the enunciated act (Wolfram, 2005). A statement can just as easily adhere to grammatical rules as not adhere to them. Every complete statement that adheres to grammatical rules makes up a "speech" (Tarello, 1974; Guastini, 1990). When it doesn't adhere to grammatical rules, it is said that a statement is "ungrammatical" (Petter, 2002).

The completeness of the statement is related to the presence of the elements formed by an idea, such as subject, verb, and

\footnotetext{
“"Every definition in law (civil) is dangerous” (Digest 50, 17, 202).
}

predicate; and then there is correctness, that is, the respectability of the grammatical rules in relation to the adequate composition of the elements of the statement: "completeness" and "correctness" of the statement, in this way, are found to be determined by the grammar of the language in question ${ }^{2}$.

"To define" consists of an attribution of meaning achieved by a statement; attribution of meaning because to define is to conceptualize with the objective of clarifying other concepts. But "to define" can refer as much to the activity of defining as to the result of the definition. So these concepts could be called the "definition-activity" and the "definition-product".

Definitions, all definitions, in order to be definitions, are composed of a "clarifying” and a "clarified" concept, in such a way that a definition may be depicted in the following manner: " $\mathrm{X}$ is defined as Y".

From this it is understandable why some authors don't go without saying: "By 'law' one must understand 'this' or '(...)”. " $\mathrm{X}$ " is the defined term or the definiendum (lat.: that which shall be defined; the term that is introduced, the clarified concept) and "Y" is the defined expression or definens (lat.: that which serves to define; term whose use is known; the clarifying concept). The "it is defined as" is the expression that appears to establish the equivalence (Ullmann, 1962). One may say, "the value of 'Pi' (definiendum) is defined as ' $3.1415926535(. .$.$) '$ (definiens)". It is understood, therefore, that the definiens isn't the "meaning" of the definiendum, but another "symbol" or "group of symbols" that according to the definition possess the same meaning as the definiendum.

Therefore, a definition, in basic terms, explains an unknown or dubious meaning by using a better known and less dubious meaning.

\section{The Definition and Its Purposes}

It is evident that aptitude for communicating does not guarantee the understanding of what is said on the part of the receiver of the message. Because as much as in conversation (be it established by words or signs) as in reading it is common for us to be faced with vocabulary that is unknown or whose

${ }^{2}$ When a statement is organized around a verb, this is said to be a "sentence" So, in these statements: 1) “John!”, 2) "What a woman!”, and 3) "Noel’s son is happy”, only statement 3) constitutes a sentence. 
meaning cannot be well-understood within the context in which it is transmitted.

To resolve this dilemma, the expedient of definition is used. With this, it may be said that one of the main reasons for defining something is to expand the vocabulary of the person for whom the definition is elaborated. But this isn't the only purpose of definitions.

Generally, definitions assist in the elimination of ambiguities, in the explanation of something, in the reduction of information, to influence attitudes, or even to avoid emotional repercussions (Copi \& Cohen, 1994):

1) Eliminating ambiguities. When a single word or expression is used to indicate two objects or distinct phenomena, it is said to have ambiguity. This is why every time it is established that a word is ambiguous this signifies that it can be understood in many different ways in common or ordinary speech. An ambiguous word, therefore, can generate as much misleading reasoning, or rather, false reasoning, as it can futile arguments which are merely verbal. Delimiting the extension of the meanings of the words constitutes a useful recourse in the elimination of such incidents;

2) Explaining something. The objective of defining a vocable is not always to clarify ambiguities; it may be intended to incorporate new knowledge. However, it doesn't only have to do with expanding vocabulary, but with formulating an adequate characterization of the objects to which the term will refer. This is the case when one defines "force", "particle", "suffrage" etc.;

3) Reducing information. Sometimes a definition is used with the object of conserving mental energy by reducing sentences. Mathematically this is what happens when exponential notation is used. This can be thought of in the trouble of frequently writing the notation of $9 \times 9 \times 9 \times 9$ $\times 9 \times 9 \times 9 \times 9 \times 9 \times 9$ instead of $9^{10}$;

4) Influencing attitudes. Besides expanding vocabulary, eliminating ambiguities, explaining something or reduceing information, definitions may have the aim of provokeing emotional reactions in whoever hears the argument or reads it. Here, the defined word constitutes a crucial element for this. This is what occurs when one defines "honor”, “weakness”, “heroism”, “cowardice”, “to look after" in a court when defending someone from an accusation of murder; or even when a reference is made to "love”, “compassion", "devotion” in a ruling concerning the practice of euthanasia. In all of these situations the objective is not to supply an "exact" or "literal” definition in terms of determined practice, but to strategically lead your listeners to establish bonds with respect to what is said;

5) Avoiding emotional repercussions. Sometimes the subjective weight of the vocable creates a disturbance which calls attention to itself and dislocates the focus of the reader through reasons of emotive association. Although sometimes it is desirable that a definition instigates subjectivity in whoever hears or reads the argument, at other times the exact opposite may be desired. For this reason, terms such as "poverty", "misery”, "wealth", etc. in an economic exposition may be substituted by letters representing them as variables in a calculation of government spending. This, as a matter of fact, occurs with frequency when characteristics of the interviewee are substituted by references free of sentimental connotation. In these cases, the definition must contain an explanation that explains the symbology with the density necessary for its adequate comprehension.

\section{A Brief Classification of Definitions}

The term "definition” in plural has been used without greater explanation. There is a reason for this: the meanings of words can be specified in many different ways. And it is exactly because of this that the act of defining can vary depending on the objective or give the general idea that it is communicated starting from a concept (Tarello, 1980; Barberis, 1998).

With the hope of gathering this diversity in an intelligible catalog, theoreticians show several indicators that are understood to be strong features of any definition, such as: 1) "object" of the definition (the thing to which it refers); 2) "function" that is carried out (the effects of the definition); 3) "modality" of the definition (the technique which is used to define) and 4) "form" (if it is explicit or implicit):

1) In the context of the first indicator, "definitions in terms of the object", we have "real" definition and "nominal" definitions. In fact, this division makes up the "great divide" of definitions, that is, whether it is a "real" or "nominal" definition which is intended. Authors affirm: when a definition corresponds to a nominal definition for the question, "what does X mean", what follows is a vocable; if it corresponds to a real definition, the question changes: "What 'thing' is X?"; and, from there, the "nature" of the object is given.

In this way, by a "real definition", the expression is understood through whatever is indicated as a thing or phenomenon seeking to emphasize, collect, reflect, or look at the immutable nucleus of the entity, the nucleus that distinguishes it from other things or phenomena. But, epistemologically, every attempt at approaching a "real" definition is doomed to failure. As far as this is concerned, it's enough to establish that there is no way to satisfactorily explain this "nature" that covers the supposed essence of the real definition; because this "nature", in final analysis, constitutes the mere subjective position of whoever affirms it.

However, observations like this haven't impeded the persistence of some theoreticians in search of this said essence. With relation to this, a large portion of mistakes are due to the phrasal constructions that formulate them, and so tend to simplify the statement which serves as the definition. It is frequently said: in the statement “'Chien' means 'dog'”, what may be apparent at first glance is that "canine" is from the root of the word chien. But what is implied here is only what in this other phrase is made explicit: that "the word chien and the word 'dog' both mean the same animal”. Weighing this, some authors, with the etimology of the terms, manifest the desire to reach this "real" meaning believing that, through this, through the search of the word's origin, they obtain the essence of the meaning, which is obviously a mistake since, when taken to its conclusion, what is obtained is probably a clarification of the use of a term in a given era.

The professor Émile Benveniste, who does not commit this error, satisfies, in every way, the curiosity about the origin:

"Thanks to the Iranian and the Indian, we reconstruct the prehistory of the Latin ius. The Indo-European word yus means 'the state of regularity, of normality that is required by ritual 
rules'. In Latin, this state is affected by the double statute that we have just distinguished in Indo-Iranian. The notion of ius allows two conditions. One is the factual situation characterized by the derivative iustus in legal expressions: iustae nuptiae 'legitamate marriage'; iusta uxor 'legitamate spouse', that is, 'in conformity with the state of ius. The other is distinguished by the expression ius dicere. Here, ius means 'the formula of normality', placing it within the conformity required. That is the fundamental idea of the notion of 'law' in Rome" (Benveniste, 1989).

"Nominal definitions" (also known as conceptualists) are those which provide the meaning of a term, name, words or symbols, since this recognizes that what is always being defined is the vocable, and not a thing. However, its backdrop consists of the idea that a word isn't a natural attribute that a man discovers, but something that is accepted or rejected when it is linked to a meaning. This position differs from the last one in the exact sense that to understand that the object of the definitions are words is to consider that to define is to make a proposition; a proposition to understand or make use of a word with a determined meaning and not the search for the essence of the entity. The nominal definitions can be distinguished by descriptive nominal definition and prescriptive nominal definitions. "Descriptive" nominal definitions are those which provide the information on how a word is being effectively used; whereas "prescriptive" definitions are those which establish how a word should be used.

2) In the second point, "definitions in terms of function", we have-and this is a simplified catalog-"lexical” definitions, "stipulatives" definitions, "redefinitions", "persuasive” definitions, and "contextuals” definitions (Copi \& Cohen, 1994).

2.1) "Lexical definitions". Of all of these, certainly the most easily encountered are lexical definitions. They are called "lexicals" (lexicographicals or verbals) because they communicate or describe the meaning of a word using other words, with the intention of clarifying how the word has been used (from lexicon in the sense of "dictionary"). They are normally called explicit definitions (or synonyms). For example: "Single” means "a non-married adult". This type of definition can be found in legal works when it is affirmed that "law" in its objective meaning signifies "a gathering of norms produced by a certain institutional apparatus". It should be observed that this definition doesn't represent an innovation in legal vocabulary. In this way, it can be affirmed that if it is said that "objective law" is understood to be "the study of the decision-making techniques of judges", because it clashes with the linguistic tradition, this definition is not correct. In these terms it is descriptive, but provides information about a use that is integral to a specific field that is under examination. Another example:

a) “Cadeira” (Portuguese for “chair”): a piece of furniture that is a seat supported by legs, with a back and, sometimes, arms;

b) "Cadeira”: a biped animal that comes out to feed at nightfall.

It is known that only definition a) integrates the definition of "cadeira" considering the common usage in the Portuguese language, so that b) is incorrect.

2.2) "Stipulatives definitions". But it is possible that one doesn't want to know what a term means, but to formulate a new definition for a term that already possesses numerous meanings. In this case, it's necessary to delimit the confines of the meaning of the vocable in its new technical version. It is this definition that is frequently called a "stipulative" definition; stipulative because it prescribes a certain use that the word must have, the use that its user establishes (Scarpelli, 1985).

With stipulation it may be said that the definition is neither true nor false, only advantageous or disadvantageous, clear or obscure, precise or imprecise, useful or not useful, suitable or not depending on its objective (Guastini, 2004). And this is due to the fact that a stipulative definition consists of a proposal of use. A stipulative definition informs how the term should or must be used from a certain moment forward (Fávero \& Villaça, 1998). In this way, the stipulation is wholly admissible from a given meaning for the Portuguese word "direito" (law) in order to serve the purposes of a specific study:

a) "Law": "A grouping of mandatory terms that determine the social relations imposed at all times by the group to which they belong" (Levy-Bruhl, 1997);

b) "Law": "A group of norms that expresses the will of the working class, directed by the Communist Party, and of the other workers led by those; whose contents are determined, in the end, by the conditions of their material existence" (Alexandrov, 1974);

c) "Law": "Historic-cultural reality ordered by an attributed bilateral form according to values of familiarity" (Reale, 1997).

2.3) "Redefinitions". It may be said that an expression (word) is vague when it lacks precision in its meaning, so that it is impossible to determine the limits of its range of application. Since ordinary usage can't serve as a resource for a solution, lexicographical definitions cannot help us to solve this problem. A "redefinition" (or explicative definition) is a definition that reduces this vagueness because, although it falls within the area of the ordinary usage of the term, this is accepted up to the point in which it does not present imprecision in order to later resolve the remainder with a stipulation. Think for example to the term "young"; "young” is clearly a vague term. How many years old should a person be to be considered young? And to no longer be young? A redefinition maintains the understanding of being a youth (For example: youth is the same in a boy or a girl) increasing to a certain age (until twenty-one years). Since redefinitions are in part lexicographical and in part stipulative, they are only in part susceptible of truth and falsity; in other words, they are truth-functional up to the point in which they conform or not to what is established by ordinary usage. As far as stipulation is concerned (in the part that corresponds to a "new" meaning) true or false are not applicable; one may only speak of convenience or inconvenience, utility or inutility, correctness or incorrectness.

2.4) "Persuasive definitions". The purpose of "persuasive" definitions consists in influencing attitudes. With this in mind, it must be observed that, for a definition to be persuasive, it is enough that it be enunciated in emotive language or in a language whose rhetorical purpose is to influence people: persuasive definitions are linked to the function that they exercise and not to a specific entity or object. Therefore, its inclusion here means that this catalog is superior to any definition and, in theory, can be used with the objective of arousing reactions of attraction as well as repulsion.

2.5) “Contextual definitions”. "Contextual” definitions indi- 
cate the meaning that a word takes in a particular linguistic situation. Unlike ordinary definitions, here the formulation technique does not allow the given equivalent expression to be substituted by any statement since it is linked to the contextualized circumstance by the clarified concept.

3) As to the technique of definition, one can distinguish denotative and connotative definitions.

The technique of denotation consists of showing the literal meaning, or rather, that which is present in dictionaries. Therefore, they are "denotative" as definitions, that is, they indicate a common constant, explicit characteristic, or property. This is not to be confused with the concept of meaning, because various denotative expressions may be applied to they same thing and vary its meaning: "soliped" and "domestic quadroped" can be applied to the term "horse", but by themselves they mean different things, because "soliped" is a term that applies to every animal whose foot has a single hoof; and "quadroped" refers to every mammal that has four feet or paws. In this way, one may say that law is "natural”, "positive", "international”, or "ancient"- all of this is law even though, clearly, they don't mean the same thing. On the other hand, in a situation where the term "doesn't have any meaning", one may say that the term in question is meaningless.

The connotative technique consists of showing suggested meanings, those meanings which result from associated ideas. Therefore, definitions are "connotative" when one wants to indicate a characteristic or property which is called common to everything called by the same name.

Because of this, when a vocable is connotative, it is conceived of in such a way that it includes everything that the term is intentionally comprised of, that is, its figurative or suggested meaning. Therefore, the same expression can be applied to equal things and produce different associations. Starting with the vocable "constant”, one can say: "continuous" or "continued", but, according to the application of the concept, it can vary in meaning as "loyal”, "unshakable”, "assiduous”, "tenacious", "right”, “durable”, "fixed” etc. These meanings which go beyond the first synonymous association constitute connotetions.

From this perspective, in establishing the meaning of a word (like "law") one can provide a connotative definition as easily as a denotative definition. Here is an example: it is affirmed that norms endowed with negative (the use of force) sanction (normative consequence) are 'law' and that, therefore, there will only exist 'law' if it is set before a grouping of punitive norms. "Operative definitions" and definitions by genre and differences are connotatives; "ostensive definitions" are denotative. In that sense:

1) "Operative definitions”. "Operative” or "operational” definitions correspond to the specification of a procedure that must be understood so that, with this understanding, one might obtain its idea through the clarification of the indicated result in practice. For example: one may demonstrate the understanding of weight by specifying the technique for weighing.

2) "Definitions by genre and difference". Definitions by "genre and specific difference" correspond to the technique of indicating firstly the class of entities to which the indicated thing belong in order to then determine the specific characteristics that separate it from other things that are in the same class. For example: Man is a "rational" animal. With the addition of "rational”, "man" ("human being”) is separated from the rest of the animals;
3) “Ostensive definitions". Another way to define something is to say what the thing is through examples; these are "ostensive" definitions. This is the case that occurs when one seeks to define "paper”, saying: "a page in a book is paper”; or when one tries to explain what a "dog" is, emphasizing common names like "Rex”, “Fido”, "Lassie” etc. It's clear that the definition that serves this function suffers severe limitations. Because its clarification depends on examples, one might imagine a village located in a remote area, and desire that it be explained ostensibly by what a skyscraper is. Without similar possibilities for this, and in the absence of the knowledge of any other locations, it will be difficult to successfully use an ostensible definition.

It may be observed, moreover, that stipulatives definitions and operatives may be used to increase the vocabulary of the person for whom they were elaborated, or to promote a way of reducing information. Lexicographical definitions in the same way serve to eliminate ambiguity and redefinition serves to reduce vagueness. Stipulative definitions serve to reduce ambiguity as well as, in determined cases, vagueness. And of course, any of them may be utilized in order to persuade, depending on how they are used.

4) As to the "form", a definition can be explicit or implicit. A definition is "explicit" when it establishes a relation between a definiendum and a definiens, between the concept to be defined and the clarifying concept. This form of defining is very common in mathematics, although within the legal field it is not frequently used. This equivalence, expressed in symbols by "=df", requires that what is to be defined appears only on one side of the equation. A definition is said to be "implicit", instead, when it clarifies the meaning of a term by means of expressions in which the term appears. An example of implicit definition can be found in the brazilian civil code, art. 93:

\section{"Goods are considered belongings which, not constituting integral parts, are destined in a lasting manner for use, service, or embellishment by another."}

\section{“Norms", “Normative Dispositions", and "Chains of Dispositions"}

Considering that texts are linguistic formulations, and that a normative text does not always have a single meaning, this can rise difficulties for its intended users, who need to know, in order to obey the norms, what the normative texts mean.

To avoid such problems, the legislator resorts to definitions. The reason is that by offering more precise terminology, one may seek to minimize the variations in meaning, so that the expectations of the intended users as far as what is commanded and what is applicable to a certain universe of cases becomes more certain. In this way, defining norms go on to fulfill an essential role in the legal domain.

Some specific observations are now necessary.

"Norm" must be understood as an interpreted normative text, or rather, the meaning of a statement present in a normative document (Guastini, 1990). Therefore, "norm” and "interpretation" are terms that go together, even though they obviously must be distinguished from one another: a normative text needs to be interpreted so that, through the description of its meaning, the norm can be obtained (Fávero \& Villaça, 2005).

The norm, in this manner, is the result of the interpretive act; its point of arrival, not of departure. The point of departure is 
the legislation, the normative documents, or the legal texts that are composed of statements elaborated with (arranged in terms of) a specific "legislative" or "nomographic" technique. As to the result of the interpretation, the normative problem is a problem which finds its problematic base in the linguistic correction of its own text and in the factual situations that inform a case:

1) The term "norm" is used to indicate the structural relation between a typical fact and a legal consequence ("If typical situation 'p' (descriptive aspect) is verified, then legal consequence ' $S$ ' (prescriptive aspect) follows”). Despite this, legislative language rarely groups description and consequence in a single text or statement. This is the reason why it is often said that a "norm fragment" corresponds to a statement that requires another in order to obtain its normative meaning, the norm N. It is interesting to observe that this "norm fragment" is known by jurists as "disposition”. In this way, "norm fragments" and "dispositions" are understood as synonymous terms; 2) Although this treatment causes no harm, perhaps it would be appropriate to now establish this idea more precisely. "Disposition" stands for "normative statement"; "norm fragment" stands for "norm". The references, therefore, are distinct. When someone mentions a "disposition", this may or may not be a part of a norm, whereas when a "norm fragment" is mentioned, the segment of the statement is part of a statement that makes up a norm. This differentiation is necessary because unintelligible dispositions (be they ungrammatical or incomplete), although they are dispositions, will not result in any norm; therefore, they can't be considered "norm fragments". Or rather, only "dispositions" that are really meaningful can be considered fragments. It is clear that a norm can result from a single provision. For example, Article 121 of the Brazilian Penal Code: Killing someone: Penalty-6 to 20 years of incarceration. In this case, the configuration is simple: $\mathrm{N}=\mathrm{D}$. However, when faced with a case where a norm results from many provisions, this configuration becomes more complex.

This is to say: $\mathrm{N}=\mathrm{D} 1$ (or Fg1) + D2 (or Fg2) + D3 (or Fg3) $+\mathrm{DN}$ (or FgN).

In this manner, with greater perceptiveness, the fragments that together form a norm constitute a "chain" (D1). So this sequence of worked fragments may be understood as a "chain of dispositions" (D1 + D2 + D3 etc.) by the interpreter in order to obtain the norm.

Let's take for example the norm that solves the problem of presidential vacancy (and this is only one of many imaginable examples). This norm is extracted from, at least, the following dispositions:

1) CF, art. 78: "The President and the Vice-President of the Republic will take office in session of the National Congress, taking the oath to maintain, defend, and fulfill the Constitution, obey the law, promote the general welfare of the Brazilian people, and sustain the union, integrity, and independence of Brazil.

If, having passed 10 days from the fixed date for taking office, the President or Vice-President, save motive of greater force, has not assumed the office, it shall be declared vacant";
2) "In case of impeachment of the President or the Vice-President, or vacancy of the respective offices, the succession to the office of the Presidency will be to call the President of the House of Representatives, the President of the National Senate, and the President of the Federal Supreme Court";

3) $\mathrm{CF}$, art. 81: "If the offices of the President and the Vice-President become vacant, an election shall be held 90 days after the opening of the last vacancy:

a) If a vacancy occurs in the last two years of the presidential term, the election for both offices will be held thirty days after the last vacancy, by the National Congress, in the manner of the law.

b) In any of these cases, the persons elected must complete the term of their predecessors."

4) CF, art. 82: "The term of the President of the Republic is four years, and shall begin in the first of January of the year following the election".

It may be observed that disposition 1) provides information with respect to what is (there being) a vacancy (what means “vacancy"), but provides no solution; disposition 2), although establishing the sequence of succession, does not resolve the problem of vacancy because it is dependent on the understanding of dispositions 1), 3), and 4). This last one regulate the period of complete execution of the Presidency and Vice-Presidency. That is, other dispositions should be cited to complete the idea of who carries out the Presidency of the House of Representatives and, if necessary, of the Federal Senate and the Federal Supreme Court. Or rather, thanks to this chain of dispositions it is possible to know what the norm is in case of succession.

The importance of definitions within this context may be called into question. This will be dealt with in the subsequent sections.

\section{Legislative Definitions}

\section{Should the Legislator Define?}

Condemnations of legislative definitions are common. It is often said that preference should be given to doctrine in supplying the meaning of legal terms that are ambiguous, vague etc., not to the legislator. The most frequent arguments are that legislative definitions impede the "progress" of the legal institutions and that to legislatively define causes politics to endanger the process. What results from this is that legislative definitions are not considered linked to the interpreters.

Concerning to the first aspect, one must establish at least two points. First, that if definitions can be modified, so can legislative definitions.

Second, as far as political danger is concerned, there is no reason to believe that the formulation of any legislative definition is worse, or better, than any other formulation. On the contrary: the use of vague and indefinite expressions is common to dictatorship periods. Such usage, which is not unknown, though principally within the area of criminal law, has been used as a principle for safety, and as an expedient of wide use by arbitrary governments.

Furthermore, we forget that a legislative definition not only accomplishes the task of providing precision to concepts, but that it also constitutes a legislative technique that can modify 
norms in a single act. Take, for example, the lowering of the legal age from 18 to 16 that is being discussed in Brazil, the basis of which is the modification of the specific norm defining legal age ${ }^{3}$.

Besides this, in every communicative act it is necessary to presuppose a minimum parameter of meaning. It is evident that the shared use between agents of the same vocabulary (semantic field) permits, in many cases, to consider solved this problem. But it is possible that one wants to perform a speech act whose content is not available in the shared language. It's clear that, because of this, since even experts need to find a parameter of use, legal controversies depend exactly from the referred absence. This is why there are situations in which the legislative definition is of utmost importance. The paradigmatic case is the example of the definition of "adulthood".

All of this, as has been illustrated, led however someone to the conclusion that legislative definitions shouldn't be considered at all, or rather that, since they are often inexact, interpreters should be free to dismiss them from consideration. This conclusion can in turn be read in two ways:

1) Legislative definitions are not always correct, and this justifies their dismission by intepreters;

2) Not all legislative definitions are prescriptive, and for this reason not all have to be considered.

With respect to thesis 1), it is not valid because it assumes the idea that there is a "correct" (or "true") definition, while, as we saw, definitions don't refer to an "essential" fact that makes it possible to choose the "correct" one. Definitions can "reproduce" a linguistic use (lexicographic definitions) or establish a new use (stipulative definitions), or, in some way, carry out both tasks (redefinitions). Therefore, when a legislator produces a definition that doesn't combine with the current use, this is clearly a stipulation, and when a definition produced by a legislator only in part reflects the current use, the legislator is redefining. What must be firmly criticized is not the incorrectness (falsity) of a definition, but legislator's lack of precision in defining an expression.

With respect to thesis 2), one must, to best understand it, injects some more precision. If it merely means 2.1 ) that not all definitions constitute a proposal of use, then it is correct, as it was previously illustrated; if it means 2.2) that not all legislator's statements result in "norms of conduct", this is also correct, because there are norms of structure whose function is to confer institutional powers (not involving, therefore, a deontic qualification of conduct). Nevertheless, neither version 2.1) nor version 2.2) allow to disregard legislative definitions.

First construction (interpretation) does not imply the above mentioned conclusion because there is no relation between the function that the legislative definition perform and its importance to the user. At least two considerations clarify how thinking otherwise would be irrational.

First, let us consider "authentic interpretations". If one is to understand that "authentic interpretations" are distinct from "legislative definitions", one might ask what justifies accepting a regulatory force in the first case and refusing it in relation to

${ }^{3}$ The PAC-Proposed Amendment to the Constitution, No. 33 of 2012, amends the wording of Articles 129 and 228 of the Federal Constitution, adding a single paragraph to provide for the possibility of disregarding criminal incapacity for minors over sixteen and under eighteen years of age by complementary law. the legislative definitions.

Second, if one is to understand that "authentic interpretations" and "legislative definitions" are the same technical regulation, it would be treated differently, which would be unusual.

Lastly, it must be noted that, as a fragment of a norm, legislative wording, whether "proposing" or "describing" a term, can be used to either draw up a norm of "conduct" as well as a norm of "structure", that is to say that one can use a legislative definition to draw up a prohibitive norm as well as to draw up a norm for the allocation of power (i.e. a definition that provides for both age groups can be used to form the parameter of a prohibitive norm or a norm that enables someone to modify a legal relationship).

The precedent thesis implicitly rely on essentialism about meaning, but to admit the possibility of "defective" definitions this assumption is not necessary. Definitions are "defective", poorly elaborated in the light of the ends for the achievement of which they're drafted. To avoid this result, legislators must improve their drafting techniques. And it is important not to forget that a "legislative definition" is part of the speech of the legislator and that, for this reason, the interpreter cannot ignore the proposal of determination of meaning it represents. No interpretive technique justifies discrediting legal materials.

\section{Legislative Definition}

As we said a "vocable" is a word or term. We shall call every term or vocable contained in a legal statement a "normative vocable" or a "normative term". It has also been said that a "statement" is part of a speech; and that a statement that forms a clause is any linguistic expression of a syntactic form (according to certain grammar) that is complete and endowed with meaning. Legal texts (or normative texts) are normative documents. They are "documents" because they are material supports or signs which evoke the existence of a determined situation or happening; they are "normative" because they result from the activity of agents provided with the power or competence to formulate them, a power or competence conferred by norms. In their most common form, "normative documents" are known as "legislation".

If "to define" is understood to be an attribution of meaning, a term or vocable is legally defined when a legal statement gives it a (totally o partially) determined meaning. A legal statement that defines a term is a "legal or legislative definition".

If "to define" is understood as an attribution of sense, a word or term is legally defined when, fully or partially, the legal wording attributes a certain sense to it. Legal wording that defines a legally defined term is, evidently, a "legislative" or "legal" definition. Therefore, any legally defined term or word is a legal or regulatory term or word.

However, the legally defined word is not a legal or regulatory term or word because it was defined by legal wording, as there are legal words not defined by legal texts. The inclusion of a word in the legislation is not dependent on its legal definition, but on its formulation by a regulatory authority. In other words, there can be legal words (created by a legislator and, therefore, present in the legislation) that have not been defined in a legislative body of a legal system. This is a legally undefined term (present in the legislation but not "defined" in it). Thus, whether it is defined or not is not the criterion for inclusion in the legislation; it is the fulfillment of the secondary rules.

In such case, the undefined legal words are "regulatory" be- 
cause they were drawn up by regulatory authorities under a legislative procedure laid down by the very legal system, and only that.

Following that conclusion, "legislative definition" must be understood as all wording that, as part of a regulatory text (a provision), indicates the meaning of some expression of the legal language, in other words, its definiendum. The objective of legislative definitions, as any other definitions, is to reduce ambiguity and vagueness and to clarify the meaning of terms to be handled by the operators of the legislative assembly. There exists, therefore, legal wording Ejl that contains word $\mathrm{X}$, and a legal definition present in legal wording Ejl, in which word $\mathrm{X}$ is defined. Both are drawn up by a regulatory authority of the legal system in question.

\section{The Stylization of Legal Definition}

Limiting our attention to what are called "explicit definitions", some notes can be made concerning their common stylization (Luzzati, 1982).

Legal definitions are commonly introduced in the following ways: 1) indirectly; 2) using a conditional clause; 3) incidenttally. Despite these variations, however, it can be said that the norms of definition fit the following formula: " $\mathrm{X}$ 's are identified by category Y".

Norms of definition are norms that fulfill exclusive and inclusive functions: inclusive regarding to the identified objects, and exclusive as they concern others. This is the case of art. 87 of Brazilian Civil Code which says: "divisible goods are those which can be divided without alteration of their substance, considerable decrease of value, or harming the use for which they are intended.”

But norms of definition can also be subdivided into conceptual norms of definition and extensional norms of definition. "Conceptual norms of definition" are those that establish the meaning of something ${ }^{4}$ whereas "extensional norms of definition” (also known as classificatories) establish attributes to a category that to them is co-extensive ${ }^{5}$.

Through the expressions "By $\mathrm{X}, \mathrm{Y}$ is understood", or " $\mathrm{X}$ designates $\mathrm{Y}$ ”, or even, "X means $\mathrm{Y}$ ”, stipulative legal definitions are generally introduced ${ }^{6}$.

"Contextual definitions" follow the structure, " $\mathrm{X}$ is $\mathrm{Y}$ when ..."; where the contextual character is explicit in the sequence $^{7}$.

\section{Are Legislative and Doctrinal Definitions Different?}

Misunderstandings and confusions arise when the sender of a message intends to refer to something about which the receiver has a doubt that leaves open more possibilities of interpretation.

\footnotetext{
${ }^{4}$ Brazilian Civil Code, Art. 42. Legal entities of external public law are foreign states and all persons who are governed by international public law.

${ }^{5}$ Brazilian Civil Code, Art. 87: "Divisible goods are those that can fractured without alteration of their substance, considerable loss of value, or loss of use as intended".

${ }^{6}$ In accordance with the main section of Article 17 of Decree 4595/64: "For the purposes of the legislation in force, financial institution are those considered to be public or private legal entities that have as the principal activity or accessory, the collection, intermediation, or application of financial resources of their own or of others, in national or foreign currency, and the custody of the value of the properties of others".

${ }^{7}$ Brazilian Civil Code, Art. 84: "The materials intended any construction, whilst not in use, shall retain their characteristic as furnishings; shall reacquire that characteristic from the demolition of any building”.
}

This is normally what happens when one mentions the term (expression) "legal language”. In fact, through "legal language” we can mean:

1) The language in which the norms are expressed (formulated);

2) The language that jurists use in their specialized duties.

In order to avoid problems, to designate the first case we will make use of the expression "legal language", while to refer to the second case we will use the expression "language of jurists". Legal language can be understood, in this way, as a normative language (language of legal texts); despite this, the language of jurists can be recognized-at least in the civil law tradition-as the speech of jurists when it assimilates legal language as its basic object.

Karl Olivecrona once wrote that "Our legal language is substantially a part of current language” (Olivecrona, 1999). Legal language, even though it is a technical language, it is expressed in natural language (Portuguese, English, Spanish, Italian, French, etc.), and it is not unusual that it depends on rules, practices, and also conventions that inform and condition the natural language of the community in which it has become part (For example: in Brazil, Portuguese).

From this it has been affirmed that there are no syntactical peculiarities in legal language that make it possible to distinguish it from natural language. This, in spite of the fact that there exists in the language of the legislator some semantic characteristics due to the influence of this in forming the meaning of some terms that it utilizes (Wrobléwski, 2003). However, the semantic richness of the natural language can be a problem, because the vagueness and ambiguity of its terms present an additional difficulty in the elaboration of normative texts (Wrobléwski, 2003).

It's clear that technical language, with the elaboration of specific terms (such as: theft, robbery etc.) can reduce the uncertainty about the meaning, but, on the other hand, increases the distance between the technical operators and the non-technical ones; and this becomes even more complicated when, for example, the question has to do with the type of language a constitution must use and the consequences of the choice effected. In fact, the more technical is constitutional language, the less intelligible it will be for the lay operator; and, the less technical it is, the more difficult it will be for the technical interpreter when attributing meaning to the normative text.

If the language of jurists depends on legal language, and if legal language depends on natural language, then language of jurists too depends on natural language. It is evident, then, that norms, normative propositions, legal language, and the language of jurists are notions that maintain strong relations (ties): legal language is the language of normative documents; the language of jurists basically is composed of propositions about norms, such as: "A norm $\mathrm{N}$ is a valid norm in Brazilian legal order”.

Keeping in mind the reconstruction of legal definitionthe answer to our present question is: legislative and doctrinal definitions differ, but meet in various ways on the linguistic plane.

Doctrinal language is basically descriptive (composed of description) even though the language of the legislator is prescriptive language. The first lies in the metalinguistic plane; the second lies in the object-language from which legal scholars elaborate their propositions. This is why one must not confuse a 
"legislative definition” with "doctrinal definitions”: a legislative definition is part of the speech of the "legislator" whereas a doctrinal definition is part of the speech of "jurists". One may then say, on one hand, that either the doctrine exercises a cognitive function-transmitting some information about normative materials - or it exercises a pragmatic persuasive function-defendingcertain normative (ethical, political) position.

\section{Some Pathologies of Legislative Definitions}

What has been said before does not mean that a legislative definition is always a good definition. In this section the main problems depending from an inadequate definition will be analyzed.

The first problem is the "problem of topography" (topographical problem). Since the objective of legislative definition is to facilitate the composition of the normative text in which a determined vocable is used (present), the rule must be the inclusion of the defined term in the same normative document. When the definition is differently codified, many serious problems can result. Nevertheless, the most fundamental difficulty is that of knowing from which of the innumerable legislative documents the definition (for a case) must be "extracted".

A second and frequent problem is the "problem of inconvenience or poor usage". As it has already been pointed out, the objective of establishing a legislative definition is that of determining the meaning of terms, phrases, or vocables present in texts or normative statements seeking to minimize semantic instability. Therefore, legislative definitions constitute an important instrument through which the legislator contrasts the ambiguity and vagueness of a usual term, making it less uncertain in the act of interpretation of different users. It is in this sense that definitions don't act upon norms (interpreted statements) but upon other statements (texts that have to be interpreted).

To fulfill this task, a definition must be employed in a way consistent with its objectives. An example of this can be the perception that a stipulative definition, being a prescription for the use of a certain vocable bringing new meaning, can compromise the transparency of the legislative message in case there is a meaning that has already been widely circulated. In this case, it's better to use a redefinition.

The third problem is the "problem of incomplete definitions". An incomplete definition lacks some element of definiens that is necessary to clarify the definiendum. And this is evidently a problem, because it is obvious that the supplied definition doesn't solve the problem of meaning, but amplifies it.

The fourth and final problem that we would like to emphasize is the "problem of circularity". There is circularity whenever the definiens overlaps totally or partially with the definiendum. In this case the offered definition produces a no result.

\section{Ten Recommendations for a Good Definition}

One of the reasons why there are difficulties in the determination of the meaning of a phrase depends the various alternative meanings with which terms are used. This is why the introduction of legislative speech (language) is only advantageous when the terms contained in the definiens arouse less controversy than those which are found in the definiendum. It's then very important that the definitions are well-formulated (Hayakawa \& Hayakawa, 1990). Therefore it is recommended that at least 10 fundamental rules be followed:

1) The term to be defined cannot appear in the defining part.

The definition definiens can't include the term being defined definiendum. A definition that violates this rule-as the following example: "A rectangle is a rectangular geometric shape"-is useless given the vicious circle it generates.

2) A definition must not be formulated in negative terms.

To be rigorous, a definition can't be formulated in negative terms. The reason for this is simple: a definition must explain how to use a term and not what it doesn't mean (how not to use it). Therefore, the following is an example of a definition to be avoided: "Solid is everything which is not liquid".

3) A definition must be useful and contain what is necessary.

A definition must be used not only to precise the technical or common use of a vocable, but also when it is used with a meaning that is not common. This is because for a definition to be useful, it must be suitable, with its use, to the objective. Exactly because of this, it is not recommended to use definitions that only reiterate current usage which will either disturb an established practice or simply be redundant. Moreover, the definition must contain what is necessary, no more and no less. The following definition contains more than is necessary: "A triangle is a polygon with three angles and three sides." The excess is the term "polygon". The following definition contains less information than is necessary: "A triangle is a polygon." The lack of the information that a triangle possesses three angles and three sides compromises the understanding of the definiendum. The presence of a term that needs to be defined compromises the intelligibility of the initial definition.

4) The definition must not contain ambiguities, be obscure, or contain figurative speech.

If the legislator intends to limit the discretion of the user (of the interpreter), then must be precise in his statements; definitions act, here, in an important manner. Ambiguous terms must be avoided because they impede an explanation of the definiendum. Terms or those that contain a figurative meaning, because they compromise the clarity of the definition.

5) There must be reciprocity between the vocable to be defined and the definition.

The fifth point is that there must be reciprocity between the vocable to be defined and the definition, in the sense that they can switch places.

6) The same term must not be defined various times in different ways.

According to this requirement distinct terms must be used to express distinct meanings, and the same terms must be used with the same meaning. If in legislation a single term is used to express many distinct meanings this will generate serious problems in the applicative field; and this may also be said of distinct terms that are employed with the same meaning.

7) Definitional dispositions must contain only the definition.

The seventh rule means that it is dangerous that a disposi- 
tion, besides defining, adds other elements to the defining provision. This because, besides the confusion of statements, since a definition is cited many times, every time there is a cross reference to the disposition that contains it it will be cited more than the mere definition.

8) Definitions must be located at the beginning of the legal text.

This is a pragmatic recommendation with the aim of making easier the attribution of to the vocables used in the sequence of dispositions. Besides this, to employ a term before giving a definition of it would make more difficult the understanding of the structure of dispositions.

9) The defined term must be made clear.

This recommendation is listed in case it is necessary to know that the vocable is being defined. One of the ways to do this is to always write what is to be defined in capital letters.

10) A definition must be self-sufficient.

This means that there must be a full definition in the statement that makes it unnecessary to search another provision for some element which completes it.

It seems clear that these recommendations are not applicable to every type of definition. For example, it doesn’t make sense to use the fifth rule in an ostensive definition. But, all in all, these rules serve as an indication of the main defects a definition can suffer, especially lexical ones.

\section{Conclusion}

Every definition in a text is a disembodied act: it suffers the effects of reality and, therefore, of its use. Or rather, the enunciated focus shouldn't be confused with the situation of communication: if the legislative definitions reveal pretensions (in the case of the legislator) this fact of the original speech requires other pieces of practical speech to be understood.

In this respect, ambiguity constitutes the main problem of a legislative definition and, in particular, syntactic ambiguity. Semantic ambiguity less so, keeping in view that this is the object of occurrence in every definition. In these terms, despite the fact that a definition is an expedient for assigning a meaning, its written transmission requires interpretation. With this, in case the legislative definition has been formulated in an ambiguous or vague manner, this compromised formulation will be fatally reflected in the understanding of the attributed meaning by the legislator. In other words, a legislative definition doesn't guarantee, in absolute terms, that the meaning attributed by the legislator to a vocable $\mathrm{X}$ will be the same meaning that the user will attribute to it: everything depends on the very construction of the legislative definition and on the practice that will result from it.

However, one must wait and see if a good definition aids in the demarcation of the area of use (besides resolving political problems relative to the peculiarities of certain sectors of law, like "criminal" law), in the same manner that a terrible definition can generate serious problems and no small grumblings among its users.

The purpose of this study has been to introduce the most sensitive technical aspects of generating better definitions

\section{REFERENCES}

Alexandrov, N. G. (1974). Teoria geral marxista-leninista do Estado e do direito. Amadora: Novo Curso.

Barberis, M., (1998). L'evoluzione del diritto. Torino: Giappichelli.

Benveniste, É. (1989). Problemas de linguística geral. São Paulo: Ed. Unicamp.

Luzzati, C. (1982). Le definizioni implicite dei giuriste. Analisi e Diritto, 1982, 215-223.

Copi, I., \& Cohen, C. (1994). Introduction to logic. New York: MacMillan.

Fávero, L. L., \& Villaça, I. (2005). La semiología. Madrid: Cortez.

Fávero, L. L., \& Villaça, I. (1999). Linguistica textual: Introdução (7th ed.). São Paulo: Cortez.

Guastini, R. (1990). Dalle fonti alle norme. Torino: G. Giappichelli.

Guastini, R. (2004). L'interpretazione dei documenti normativi. Milano: A. Giuffrè.

Hayakawa, S. I., \& Hayakawa, A. R. (1990). Language in thought and action. New York: Harcourt.

Levy-Bruhl (1997). Sociologia do direito. São Paulo: Martins Fontes.

Olivecrona, K. (1999). Lenguaje jurídico y realidad. México City: BÉFD.

Petter, M. (2002). Introdução à linguística. São Paulo: Contexto.

Reale, M. (1997). Filosofia do direito (9th ed.). São Paulo: Saraiva.

Scarpelli, U. (1985). Contributo alla semantica del linguaggio normativo. Milano: Giuffrè.

Tarello, G. (1974). Diritto, enunciati, usi (Studi di teoria e metateoria del diritto). Bologna: Il Mulino.

Tarello, G. (1980). L'interpretazione della legge. Milano: Giuffrè Editore.

Ullmann, S. (1962). Semantics: An introduction to the science of meaning. Oxford: Blackwell.

Wolfram, S. (2005). The Oxford companion to philosophy. Oxford: Oxford University Press.

Wrobléwski, J. (2003). Sentido y hecho en el derecho. México City: BEFDP. 